\title{
Glutamine: Beneficial to prevent oral mucositis in Mexican children with acute lymphoblastic leukemia?
}

\author{
Miriam R. Caselin-García1, 2, 3, Katja Stein¹, 2, 3, Miguel R. Kumazawa-I chikawa³, Oscar González- \\ Ramella $^{1,2}$, Edgar M. Vásquez-Garibay ${ }^{3}$, Sergio Gallegos-Castorena ${ }^{1,2}$, Sonny Flores-Navarro ${ }^{1,2}$, \\ Pablo A. Chávez-Panduro ${ }^{1,2}$, Fernando Sánchez-Zubieta ${ }^{1,2}$ \\ 1. Institute for Research on Cancer in Childhood and Adolescence, University of Guadalajara, Guadalajara, Mexico. 2. \\ Department of Pediatric Hematology and Oncology, Hospital Civil de Guadalajara "Dr. Juan I. Menchaca”, Guadalajara, \\ Mexico. 3. Institute of Human Nutrition, University of Guadalajara, Guadalajara, Mexico
}

Correspondence: Katja Stein. Address: 750 Salvador Quevedo y Zubieta, 44340 Guadalajara, Jalisco, México. Email: katja2mx2004@hotmail.com

Received: May 28, 2013

DOI : $10.5430 / \mathrm{jhm} . \mathrm{v} 3 \mathrm{n} 1 \mathrm{p} 49$
Accepted: July 14, 2013

Online Published: July 25, 2013

\section{Abstract}

Background: Oral mucositis (OM) is a common side effect of antineoplastic-drug administration. It is frequently related to risk of infection and poor intake of foods and fluids. This might adversely affect the patients' nutritional status, cause dose reductions, prolong treatment time and length of hospital stay, and increases costs of treatment.

Aim: To investigate if the use of glutamine (Gln) administered by mouthwash during methotrexate(MTX)-chemotherapy in the consolidation-phase reduces oral mucositis in children with acute lymphoblastic leukemia (ALL).

Procedure: A double blind randomized study was conducted from January 2009 to December 2010 with two independent samples. Eligible patients were children with ALL between 0-18 years. These patients were randomized into two groups: an experimental-group and a placebo-group, which received Gln or maltodextrin as placebo.

Results: OM occurred in $10.7 \%$ of the experimental group and $13.6 \%$ in the control group, with no significant difference in the severity or incidence of OM.

Conclusions: There was no significant difference in the prevention of OM by mouthwash with Gln vs. placebo. Proper oral hygiene and an adequate hyperhydration regimen before and during MTX-chemotherapy, as well as the measurement of serum-methotrexate concentrations are likely to be sufficient to prevent OM.

\section{Key words}

Oral mucositis, Glutamine, Acute lymphoblastic leukemia, Children

\section{I ntroduction}

Chemotherapy treatment in children with acute lymphoblastic leukemia (ALL), especially methotrexate (MTX) administration, may cause oral mucositis (OM), which affects the rapidly dividing mucosal cells of the gastrointestinal tract ${ }^{[1]}$. This toxicity is frequently related to a higher risk of infections, dysgeusia, dysphagia and a poor intake of food and 
fluids that could affect the patient's nutritional status ${ }^{[2]}$. In addition, OM may prolong the treatment time, length of hospital stay, as well as increase costs of treatment ${ }^{[3,4]}$.

OM has been associated with a decreased quality of life and emotional state in terms of mood disturbance, depression, and anger in patients receiving chemotherapy ${ }^{[4]}$.

The prevalence of OM is variable and has been reported in $18 \%$ to $52 \%$ of patients who received standard-doses of chemotherapy ${ }^{[5]}$ and younger patients seem to have an increased risk of chemotherapy-induced $\mathrm{OM}^{[6]}$.

In recent years different therapies have been investigated ways to prevent OM such as antibiotic pastille or paste, cryotherapy or glutamine. However there is no standard prophylactic therapy ${ }^{[5,7]}$.

Glutamine (Gln) is a dispensable amino acid that regulates the intracellular redox potential. Previous clinical studies suggest that this amino acid might reduce proinflammatory cytokine cascade and can increase collagen and fibroblasts synthesis improving mucosal wound healing ${ }^{[8]}$. But there is still controversy about the use and effectiveness of Gln on OM prevention ${ }^{[9]}$. Clinical research studies have demonstrated that Gln can reduce and even prevent the incidence and severity of $\mathrm{OM}^{[8,10]}$, however, other studies could not confirm these results ${ }^{[10,11]}$. Therefore, up to now it is not possible to consider the use of Gln as evidence-based standard therapy for OM treatment ${ }^{[5]}$.

The aim of this study was to investigate if the use of Gln administered by mouthwash during MTX-chemotherapy in the consolidation-phase could prevent or reduce OM in Mexican pediatric patients with ALL from 0 to 18 years.

\section{Patients and methods}

The study was a randomized, double-blind, placebo-controlled trial. Those patients who did not perform adequately mouthwashes or patients whose condition worsened were excluded (see Figure 1).

This project was approved by the Ethics Committee of the Civil Hospital in Guadalajara "Dr. Juan I. Menchaca”. Children between 0 to 18 years with newly diagnosed ALL and without Down Syndrome undergoing consolidation therapy were eligible upon written consent of parents. The patients were treated with the protocol Guadalajara 2007 adapted from St. Jude Children's Research Hospital, Memphis, TN and the Children’s Oncology Group (see Figure 2).

The patients were randomized to an experimental group, which received a solution of $10 \mathrm{~g}$ of Gln (provided by PiSA pharmaceutical ${ }^{\circledR}$, Guadalajara, Mexico) in $20 \mathrm{~mL}$ of water and a control group with an equivalent quantity of a placebo (maltodextrin) twice daily from the first day and during ten days of chemotherapy. The patients swished the mouthwash during one minute and then expectorated the solution. They were also instructed not to drink liquid or eat solid foods for at least thirty minutes after the mouthwash. Before starting the MTX-cycle, every day during hospitalization and as outpatient at the 10th day, the oral mucosa of the patients were assessed by a trained dentist applying the National Cancer Institute Common Terminology Criteria for Adverse Events version 3.0 ${ }^{[12]}$.

The nutritional status of all patients was evaluated at the beginning of each MTX-cycle and at the 10th day afterwards, when patients attended the follow up visit at the day clinic. Weight for Height (W/H) was estimated with EPI Info (2000) program using the National Center for Health Statistics/World Health Organization reference standards $1978{ }^{[13]}$ and the body mass index (BMI), arm muscle area (AMA) and arm fat area (AFA) were calculated using the Frisancho (1990) reference ${ }^{[14]}$. All indicators were expressed as $Z$ scores and a deficit was considered when the W/H, BMI, AMA and AFA were less than -1 SD from the median according to the Mexican Official Norm ${ }^{[15]}$ and WHO Standards.

Student $\mathrm{T}$ test was used to evaluate differences between groups. U-Mann-Whitney test was applied to assess differences on the continuous test variables (anthropometric indices, age, Gln and placebo) and dichotomous variables (gender, OM and 
grade of OM) were assessed with Fisher's exact test and Chi-square test. We used SPSS 17.0 for Windows and EPI Info 2000 to analyze the data. A $P$-value of 0.05 or less was considered to be statistically significant.

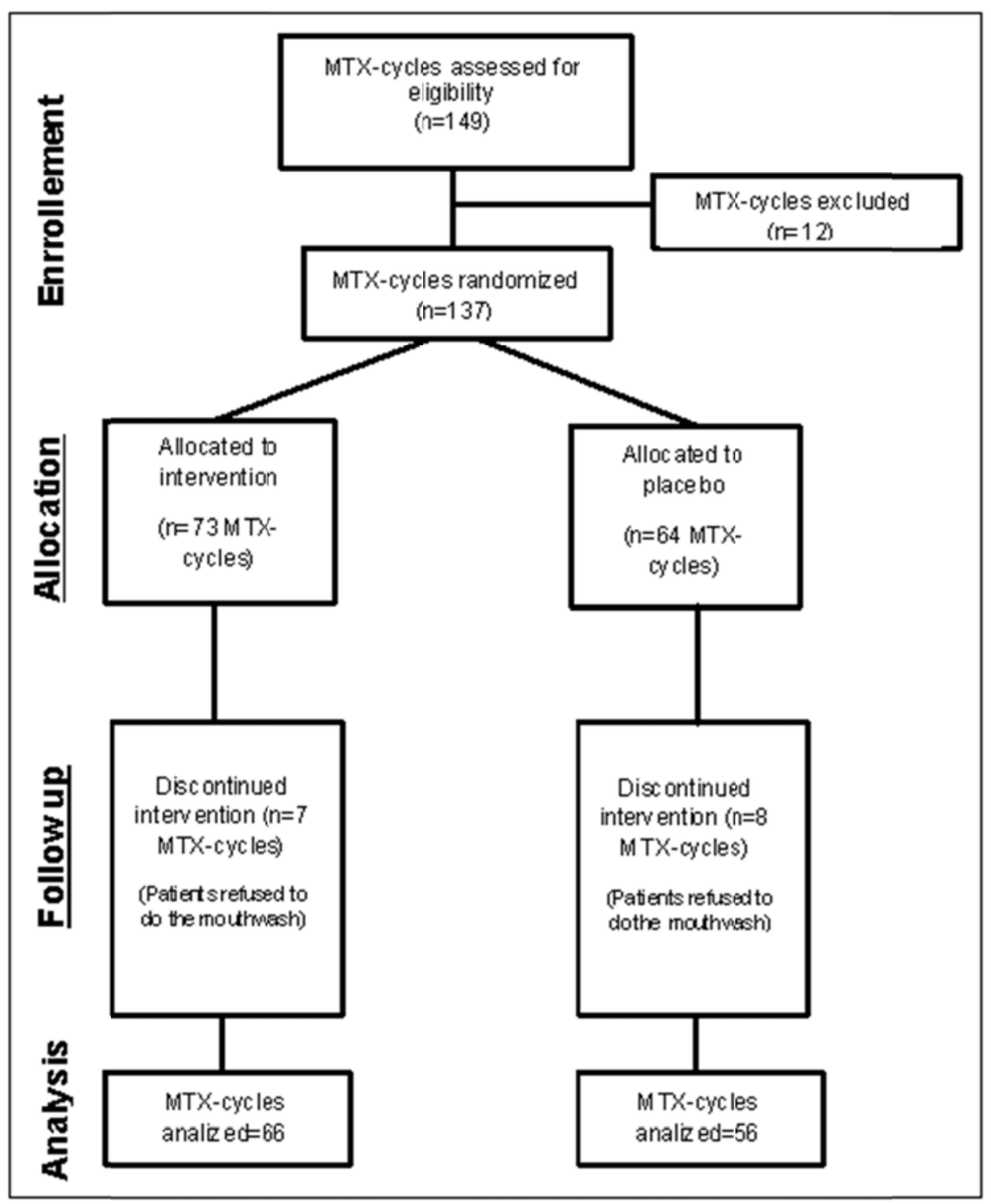

Figure 1. Study design

\section{Results}

A total of 122 cycles of methotrexate-chemotherapy were evaluated of 38 randomly assigned patients, with an average of 3.2 MTX-cycles with Gln or placebo mouthwashes per patient. The reason that some patients could not be evaluated during the four MTX-cycles of the consolidation chemotherapy was due to mouthwash noncompliance. The Gln mouthwash was used in 66 whereas the placebo solution in 56 MTX-cycles. The average age in the control and experimental group was $7.0 \pm 4.3$ and $6.6 \pm 3.6$ years respectively, and no statistically difference of age, gender, number of cycles of chemotherapy with MTX and dosage of the drug in relation to the risk of ALL were found. Table 1 describes the doses of MTX. No significant difference was recorded between both groups. 


\section{Consolidation therapy (This is repeated every 2 weeks for two months $=4$ cycles.)}

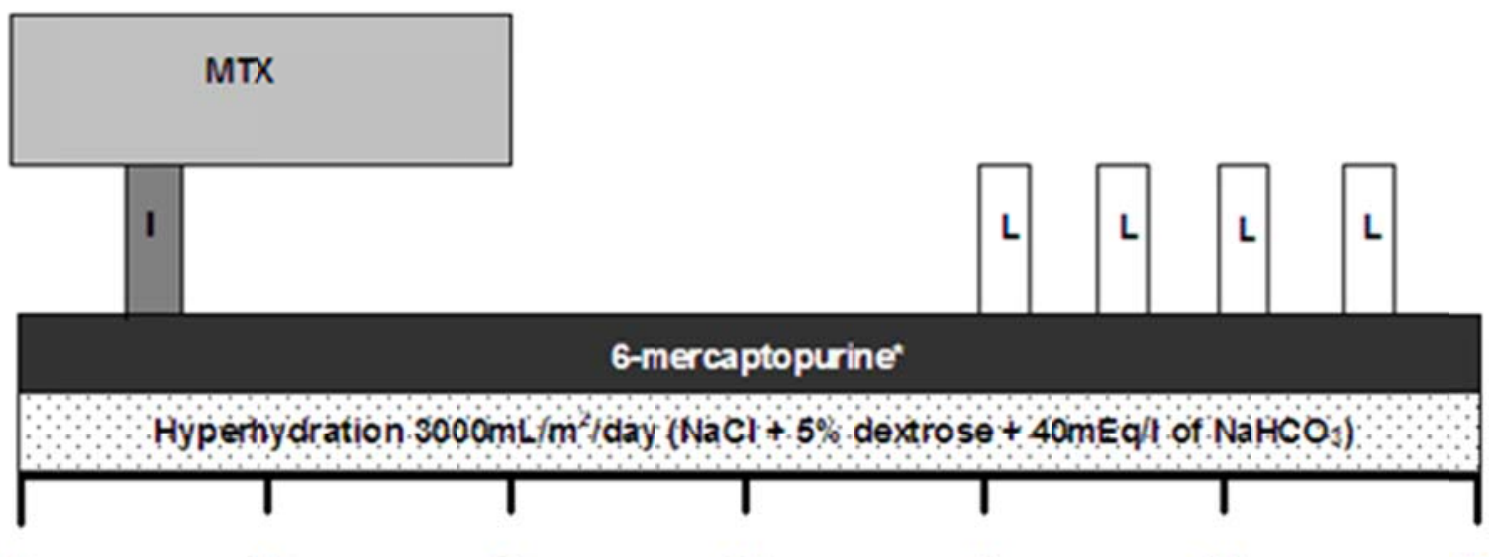
Hours 0
12
24
36
48
60
72

I. 1 ercaptopurine was administered at 25 a $50 \mathrm{mg} / \mathrm{m}^{2} /$ day during eight weeks.

I= Triple intrathecal chemotherapy (TIC), one dose was administered shortly after the I.ITX-bolus infusion.

$\mathrm{L}=$ Leucovorine doses were $15 \mathrm{mg} / \mathrm{m}^{2}$ in bolus infusion every $6 \mathrm{~h}$ for 4 doses.

MTX doses were: $5.0 \mathrm{~g} / \mathrm{m}^{2}$ for high risk ALL and $2.5 \mathrm{~g} / \mathrm{m}^{2}$ for standard risk ALL (33\% administered by bolus and $67 \%$ by intravenous infusion for 23 hours after bolus infusion).

Figure 2. Protocol Guadalajara 2007

The means and \pm SD of anthropometric data of both study groups are given in Table 2. Before the first MTX-treatment the W/H index and BMI showed significant differences between both groups $(P<0.05)$ but all patients presented an adequate nutritional status according to their W/H index and the BMI, AMA and AFA indicators. During the MTX-cycles, no significant intra- or intergroup differences of the anthropometric indices and indicators were found.

The incidence and intensity of OM (see Table 3) showed no significant difference between both groups and no relation in the incidence of $\mathrm{OM}$ in relation to the dose of methotrexate was found.

Table 1. MTX administration in both study groups

\begin{tabular}{lll}
\hline & Control group & Experimental group \\
\hline Number of evaluated MTX-cycles & 56 & 66 \\
MTX-cycles with standard risk ALL $\left(2.5 \mathrm{~g} / \mathrm{m}^{2}\right)$ & 5.4 & 21.2 \\
MTX-cycles with high risk ALL $\left(5.0 \mathrm{~g} / \mathrm{m}^{2}\right)$ & 94.6 & 78.8 \\
\hline
\end{tabular}

Table 2. Anthropometric characteristics of both study groups (mean of Z score \pm SD) before the first MTX chemotherapy

\begin{tabular}{llll}
\hline & $\begin{array}{l}\text { Control group } \\
(\mathbf{n = 5 6 )}\end{array}$ & $\begin{array}{l}\text { Experimental group } \\
(\mathbf{n = 6 6 )}\end{array}$ & $\boldsymbol{P}$ \\
\hline Weigh/Height & $0.58 \pm 1.38$ & $0.05 \pm 1.10$ & 0.03 \\
BMI & $0.53 \pm 1.33$ & $-0.09 \pm 1.19$ & 0.02 \\
AMA & $-0.49 \pm 1.24$ & $-0.92 \pm 0.66$ & 0.10 \\
AFA & $-0.42 \pm 1.15$ & $-0.46 \pm 0.93$ & 0.58 \\
\hline
\end{tabular}


Table 3. Severity of OM in both study groups

\begin{tabular}{llllll}
\hline \multirow{2}{*}{ Oral mucositis grade } & \multicolumn{2}{c}{ Control group } & & \multicolumn{2}{c}{ Experimental group } \\
\cline { 2 - 3 } \cline { 5 - 6 } & $\mathbf{n}$ & $\mathbf{\%}$ & & $\mathbf{n}$ & \% \\
\hline Grade 0 & 50 & 89.3 & 57 & 86.4 \\
Grade I & 2 & 3.6 & 2 & 3.0 \\
Grade II & 4 & 7.1 & 6 & 9.1 \\
Grade III & 0 & 0.0 & 1 & 1.5 \\
Grade IV & 0 & 0.0 & & 0 & 0.0 \\
\hline Total & 56 & 100.0 & 66 & 100.0 \\
\hline
\end{tabular}

\section{Discussion}

The appearance of OM is a common dose-limiting toxicity of MTX-treatment in pediatric patients with ALL, which may be meaningful for the overall treatment outcome. A reduction of the dosage, or a delay of the administration in response to the toxicity, decreases the therapeutic effect of the treatment and consequently the outcome. In addition, dysphagia and oral pain may cause a low dietary intake, which affects the nutritional status and has an impact on the quality of life.

In this study the overall incidence of OM was $12.3 \%$, the experimental group presented $13.6 \%$, and the control group 10.7\%. In other studies with children with ALL where high doses of MTX were used, elevated incidences of OM were reported as in the investigation made by Figliolia et al. where $46 \%$ of OM were detected ${ }^{[16]}$ or in the study of Viera et al. where an incidence of $52.4 \%$ of OM were found ${ }^{[17]}$ and Ponce-Torres observed $38.8 \%$ of OM in the same group of patients ${ }^{[18]}$.The reduction of OM observed in our Pediatric Hematology-Oncology Department over the last years is probable due to a better monitoring of the oral hygiene after the incorporation of a dentist to our multidisciplinary treatment team. It has been reported recently that the state of prior oral health can influence decisively in the appearance of mucositis ${ }^{[19]}$ and a professional oral health care may reduce the incidences of OM as evidenced by Kashiwazaki et al ${ }^{[20]}$.

Furthermore an optimal hyperhydration schedule in each patient who receives MTX may influence the occurrence of OM. Adequate hyperhydration prevents the drug from precipitating in renal tubules avoiding nephrotoxicity, which would delay the elimination of the drug causing toxicity. In addition, since 2009 serum MTX levels are measured after 24h, 36h and 48h of MTX-administration in our Pediatric Hematology-Oncology Department. This allows to modify (if necessary) the dosage of the drug in the next cycle of chemotherapy and the ability to adjust the dosage and frequency of folinic acid rescue to avoid further toxicities.

In recent years an increasing number of pharmacological interventions have been used in order to prevent OM. A systematic review identified that the polymixin/tobramycin/amphotericin (PTA) antibiotic pastille/paste, cryotherapy and keratinocyte growth factor, aloe vera and honey have been effective in OM prevention ${ }^{[21]}$. Nevertheless, clinical trials with Gln showed discrepancies about its effectiveness in the prevention or decrease of $\mathrm{OM}^{[8,10]}$.

In our study Gln was used as a mouthwash (10 g of Gln and an equivalent quantity of a placebo twice daily) and the comparison of the incidence and intensity of OM in the experimental group vs. the control group showed no significant difference. These results differ from other authors where different doses and administration were used. Anderson et al. for instance realized one study with $2 \mathrm{~g} \mathrm{Gln} / \mathrm{m}^{2}$ twice/day during the chemotherapy administration and for at least 14 additional days ${ }^{[22]}$ and in another investigation in patients undergoing bone marrow transplantation (BMT) $4 \mathrm{~g}$ Gln $/ \mathrm{m}^{2} / \mathrm{day}$ or placebo were administered from admission until day $+28{ }^{[23]}$. In both studies they observed a significant decrease in the 
intensity of OM and a decreased duration of mouth pain. Peterson et al. utilized "Saforis" which is composed of glutamine vs. placebo. It was administered orally at a dose of $2.5 \mathrm{~g}$ per $5 \mathrm{~mL}$ three times per day and it was found to be safe and effective for preventing and treating OM in patients receiving mucotoxic cancer chemotherapy ${ }^{[8]}$. Fukui et al. used a nutritional supplement containing Gln and their results suggest that Gln supplement has preventive and/or reducing effects on $\mathrm{OM}^{[24]}$.

However the results of our study concur with the findings of Jebb et al. who used a similar dose of $16 \mathrm{~g}$ of Gln or placebo daily with the first cycle of treatment in a cross-over trial. Okuno et al. administered $4 \mathrm{~g}$ of Gln or an identical-appearing placebo twice daily for 14 days beginning on the first day of chemotherapy and Ward et al. conducted a study where the Gln doses used were $0.35,0.5$ and $0.65 \mathrm{~g} / \mathrm{kg}$. In all the last three clinical trials mentioned, the dose and schedule of Gln used did not show significant effects of Gln on $\mathrm{OM}^{[10,11,25]}$.

Another interesting finding was that a patient from our experimental group suffered OM after three of four MTX-cycles, despite the use of Gln mouthwash. This could be due to a single-nucleotide polymorphism (SNP) of the child that predisposes this patient to present toxicity with MTX. Ramírez, et al. observed a significant association $(P=0.031)$ among patients carrying the SNP of methyl tetrahydrofolate reductase (MTHFR) CC and the development of OM in Mexican children with ALL ${ }^{[26]}$. Another study by Lopez-Lopez et al. analyzed polymorphisms in genes and found a statistically significant association between MTX plasma concentration and some genotype $(P=0.030)$. They confirmed the suitability of MTX plasma levels as a toxicity marker and the importance of identifying polymorphisms in children with ALL for monitoring patients at risk of low-MTX clearance in order to avoid MTX-related toxicity ${ }^{[27]}$. However, the limitation of our study was the lack of determination of SNP of our patients. Further studies are needed to demonstrate if there is a difference in the incidence of OM in those patients who cleared the MTX after 24 hours vs. 36 hours vs. 48 hours.

In investigations with Gln where improvements of OM were observed, Gln was administered in parenteral nutrition or in mouthwashes which the patient had to swallow as well. In the present study, our multidisciplinary team decided that the patients had only to swish with the Gln solution and then to expectorate it because Gln might inhibit the action of 6-mercaptopurine because of the role of Gln as a precursor of nucleotides as purine and pyrimidine. It is important to note that the current treatment protocol provided to our pediatric patients with ALL which includes the care of a multidisciplinary team, is quite effective with a low incidence of OM with or without glutamine mouthwash as evidenced by a complete remission in $92 \%$ of the patients with an overall 4-year disease free survival (DFS) of $73 \%$. This data is in accordance compared to other countries in Latin-America such as Brazil where the 5-year DFS estimate was $63 \%{ }^{[28]}$. Bonilla et al. reported an overall 4-year DFS of $48 \pm 6 \%$ in El Salvador ${ }^{[29]}$. On the other hand, Vergara et al. observed in Cuba an overall 4-year DFS of $80 \%{ }^{[30]}$.

Regarding the nutritional status before the first MTX-chemotherapy, we did not find significant differences between the Z-scores of the anthropometric indicators and patients maintained an adequate nutritional status during the treatment with MTX. Numerous patient-related factors as the BMI may influence the risk of developing $\mathrm{OM}^{[31,32]}$. A poor nutritional status seems to interfere with mucosal regeneration by decreasing cellular migration and renewal ${ }^{[33]}$. It is possible that the low incidence of OM in our patients did not affect their food intake.

The trend to have multidisciplinary teams also in developing countries as Mexico might be reflected by a decrease of toxicity and improved survival. In our department, a Nutrition Unit is responsible for monitoring closely the nutritional status of the patients and for early nutritional interventions, a Psychology Unit conducts occupational therapy, applying the Ludic Model of Play to relieve depression, anxiety and fear in children which could influence appetite and caloric intake. The Dentist cares the oral hygiene and health and the social workers create networks that help with the sponsorship of patients from low-income families. As evidenced a multidisciplinary team in developing countries can improve the quality of life and outcomes of cancer patients during the chemotherapy treatment. In this study our findings does not support Gln as a supportive care agent in cancer treatment protocols. 
A proper oral hygiene and an adequate scheme of hyperhydration before and during the administration of MTX as well as the measurement of serum drug concentrations are likely to be sufficient to prevent and maintain a low incidence of OM in a Pediatric Hematology-Oncology Department.

There is a need for further well designed, conducted trials with a sufficient numbers of participants to perform subgroup analyses by age, type of cancer and chemotherapeutic agents, this will allow the ability to analyze which doses and form of administration of Gln might be useful to prevent or reduce the OM. Additionally, evaluation of the role of the SNP of MTHFR or another enzyme or gene related to the appearance of OM may be explored. The aim of these scientific efforts is to improve the quality of life of patients during chemotherapy, and avoid side effects of OM such as pain and low dietary intake that could affect nutritional status.

\section{Acknowledgement}

The authors wish to acknowledge to PiSA pharmaceutical ${ }^{\circledR}$ for their contribution of glutamine and placebo used in this study, and the helpful comments and criticisms of Elena J. Ladas, MS, RD from the Columbia University.

\section{Conflict of interest}

The authors declare that they have no conflict of interest.

\section{References}

[1] Noé J. L-Glutamine Use in the Treatment and Prevention of Mucositis and Cachexia: A Naturopathic Perspective. Integr Cancer Ther. 2009; 8(4): 409-15. PMid:19942578 http://dx.doi.org/10.1177/1534735409348865

[2] Kostler WJ, Hejna M, Wenzel C, et al. Oral mucositis complicating chemotherapy and/or radiotherapy: options for prevention and treatment. CA Cancer J Clin. 2001; 51(5): 290-315. PMid:11577493 http://dx.doi.org/10.3322/canjclin.51.5.290

[3] Lopez-Castano F, Onate-Sanchez RE, Roldan-Chicano R, et al. Measurement of secondary mucositis to oncohematologic treatment by means of different scale. Review. Med Oral Patol Oral Cir Bucal. 2005; 10(5): 412-21. PMid:16264377

[4] Eilers J, Million R. Clinical update: prevention and management of oral mucositis in patients with cancer. Semin Oncol Nurs. 2011; 27(4): e1-16. PMid:22018411 http://dx.doi.org/10.1016/j.soncn.2011.08.001

[5] Saadeh CE. Chemotherapy- and radiotherapy-induced oral mucositis: review of preventive strategies and treatment. Pharmacotherapy. 2005; 25(4): 540-54. PMid:15977916 http://dx.doi.org/10.1592/phco.25.4.540.61035

[6] Sonis ST. Oral mucositis in cancer therapy. J Support Oncol. 2004; 2(6 Suppl 3): 3-8. PMid:15605918

[7] Sharma R, Tobin P, Clarke SJ. Management of chemotherapy-induced nausea, vomiting, oral mucositis, and diarrhoea. Lancet Oncol. 2005; 6(2): 93-102. http://dx.doi.org/10.1016/S1470-2045(05)01735-3

[8] Peterson DE, Jones JB, Petit RG. Randomized, placebo-controlled trial of Saforis for prevention and treatment of oral mucositis in breast cancer patients receiving anthracycline-based chemotherapy. Cancer. 2007; 109(2): 322-31. PMid:17154160 http://dx.doi.org/10.1002/cncr.22384

[9] Decker-Baumann C, Buhl K, Frohmuller S, et al. Reduction of chemotherapy-induced side-effects by parenteral glutamine supplementation in patients with metastatic colorectal cancer. Eur J Cancer. 1999; 35(2): 202-7. http://dx.doi.org/10.1016/S0959-8049(98)00389-X

[10] Okuno SH, Woodhouse CO, Loprinzi CL, et al. Phase III controlled evaluation of glutamine for decreasing stomatitis in patients receiving fluorouracil (5-FU)-based chemotherapy. Am J Clin Oncol. 1999; 22(3): 258-61. PMid:10362332 http://dx.doi.org/10.1097/00000421-199906000-00009

[11] Jebb SA, Osborne RJ, Maughan TS. 5-fluorouracil and folinic acid-induced mucositis: no effect of oral glutamine supplementation. Brit J Cancer. 1994; 70: 732-735. PMid:7917930 http://dx.doi.org/10.1038/bjc.1994.385

[12] NCI. Common Terminology Criteria for Adverse Events v3.0 (CTCAE). 2006.

[13] WHO. A growth chart for international use in maternal and child care. Guidelines for primary Health care personnel. 1978.

[14] Frisancho A. Anthropometric standards for the assessment of growth and nutritional status. The University of Michigan Press; 1990.

[15] Health-Secretary, Mexican Official Norm NOM 031-SSA2-1999. Official Journal of the Federation; 1999. 
[16] Figliolia SL, Oliveira DT, Pereira MC, et al. Oral mucositis in acute lymphoblastic leukaemia: analysis of 169 paediatric patients. Oral Dis. 2008; 14(8): 761-766. PMid:18761642 http://dx.doi.org/10.1111/j.1601-0825.2008.01468.x

[17] Viera N, Rojas Morales T, Griman Arrieta D. Mucositis oral en pacientes pediátricos con cáncer: Relación con la neutropenia y protocolo de tratamiento. Cienc Odontol. 2007; 4(3): 122-129.

[18] Ponce-Torres E, Ruiz-Rodriguez MS, Alejo-Gonzalez F, et al. Oral manifestations in pediatric patients receiving chemotherapy for acute lymphoblastic leukemia. J Clin Pediatr Dent. 2010; 34(3): 275-9. PMid:20578668

[19] Hernandez-Fernandez A, Onate-Sanchez RE, Cabrerizo-Merino MC, et al. Influence of oral health on mucositis in patients undergoing hematopoietic progenitor cell transplantation (HPCT). Med Oral Patol Oral Cir Bucal. 2012; 17(1): e94-e101. PMid:22157660 http://dx.doi.org/10.4317/medoral.16997

[20] Kashiwazaki H, MatsushitaT, Sugita J, et al. Professional oral health care reduces oral mucositis and febrile neutropenia in patients treated with allogeneic bone marrow transplantation. Support Care Cancer. 2012; 20(2): 367-73. PMid:21328006 http://dx.doi.org/10.1007/s00520-011-1116-x

[21] Worthington HV, Clarkson JE, Bryan G, et al. Interventions for preventing oral mucositis for patients with cancer receiving treatment. Cochrane Database Syst Rev. 2010; 12: 1-265

[22] Anderson PM, Schroeder G, Skubitz KM, Oral glutamine reduces the duration and severity of stomatitis after cytotoxic cancer chemotherapy. Cancer. 1998; 83(7): 1433-9. http://dx.doi.org/10.1002/(SICI)1097-0142(19981001)83:7<1433::AID-CNCR22>3.0.CO;2-4

[23] Anderson PM, Ramsay NK, Shu XO, et al. Effect of low-dose oral glutamine on painful stomatitis during bone marrow transplantation. Bone Marrow Transplant. 1998; 22(4): 339-44. PMid:9722068 http://dx.doi.org/10.1038/sj.bmt.1701317

[24] Fukui T, Itoh Y, Orihara M, et al. [Elental Prevented and Reduced Oral Mucositis during Chemotherapy in Patients Esophageal Cancer]. Gan To Kagaku Ryoho. 2011; 38(13): 2597-601. Japanese. PMid:22189225

[25] Ward E, Smith M, Henderson M, et al. The effect of high-dose enteral glutamine on the incidence and severity of mucositis in paediatric oncology patients. Eur J Clin Nutr. 2009; 63(1): 134-40. PMid:17728695 http://dx.doi.org/10.1038/sj.ejcn.1602894

[26] Ramírez-Pachecho A, Moreno-Galván M, Reyes-Maldonado M. Farmacocinética del metotrexato en pacientes pediátricos con leucemia linfoblástica aguda. 2010.

[27] Lopez-Lopez E, Martin-Guerrero I, Ballesteros J, et al. Polymorphisms of the SLCO1B1 gene predict methotrexate-related toxicity in childhood acute lymphoblastic leukemia. Pediatr Blood Cancer. 2011; 57(4): 612-9. PMid:21387541 http://dx.doi.org/10.1002/pbc.23074

[28] Howard SC, Pedrosa M, Lins M, et al. Establishment of a pediatric oncology program and outcomes of childhood acute lymphoblastic leukemia in a resource-poor area. JAMA. 2004; 291(20): 2471-5. PMid:15161898 http://dx.doi.org/10.1001/jama.291.20.2471

[29] Bonilla M, Moreno N, Marina N, et al. Acute lymphoblastic leukemia in a developing country: preliminary results of a nonrandomized clinical trial in El Salvador. J Pediatr Hematol Oncol. 2000; 22(6): 495-501. PMid:11132215 http://dx.doi.org/10.1097/00043426-200011000-00004

[30] Vergara-Domínguez B, Cedré Hernández T, Martínez-Cárdenas L, et al. Supervivencia y calidad de vida de pacientes con leucemia linfoide aguda: Resultados del Hospital Pediátrico «José Luis Miranda»(1969-2003). Revista Cubana de Pediatría. Ciudad de la Habana. Vol. 77. No. 3. (Julio - diciembre 2005). ISSN 0034-753. [MEDLINE].

[31] Cheng KK, Goggins WB, Lee VW, et al. Risk factors for oral mucositis in children undergoing chemotherapy: a matched case-control study. Oral Oncol. 2008; 44(11): 1019-25. PMid:18329325 http://dx.doi.org/10.1016/j.oraloncology.2008.01.003

[32] Fadda G, Campus G, Luglie P. Risk factors for oral mucositis in paediatric oncology patients receiving alkylant chemotherapy. BMC Oral Health. 2006; 6: 13. PMid:17049085 http://dx.doi.org/10.1186/1472-6831-6-13

[33] Bensadoun RJ, Magne N, Marcy PY, et al. Chemotherapy- and radiotherapy-induced mucositis in head and neck cancer patients: new trends in pathophysiology, prevention and treatment. Eur Arch Otorhinolaryngol. 2001; 258(9): 481-7. PMid:11769997 http://dx.doi.org/10.1007/s004050100368 